\title{
Application of New Steel Strip Material in Lining Structure Reinforcement for Highway Tunnel Engineering
}

\author{
Lin-Sheng XU ${ }^{1, a,{ }^{*}, \text { Zhi-Yuan WANG }}{ }^{1, b}$ \\ ${ }^{1}$ School of Civil Engineering \& Architecture, Chongqing Jiaotong University, Chongqing 400074, \\ China \\ a1651941117@qq.com, b401884351@qq.com \\ ${ }^{*}$ Corresponding author
}

Keywords: Highway Tunnel Engineering, Material of New Steel Strip, Reinforcement of Lining Structure.

\begin{abstract}
The traditional reinforcement method of highway tunnel lining crack is difficulft to constuct and brings about structure damage. The reinforcement method of new steel strip with carbon fiber and crack perfusion not only constructs simply, but also brings less destruction to the lining structure and has well value of practical application and application prospect. The new steel strip is new material of tunnel structure reinforcement and its main material is Q235A, elastic modulus 210GPa, Poisson's ratio 0.3 , severe $76.93 \mathrm{~N} / \mathrm{m}^{3}$. The main physical and mechanical parameters of new steel strip with width $220 \mathrm{~mm} \times 2.5 \mathrm{~mm}$ thickness are as follows: the cross-sectional area is $564.4 \mathrm{~mm}^{2}$; yield load is $68.3 \mathrm{KN}$; yield strength is $34317 \mathrm{KN}$; breaking force is $246.7 \mathrm{KN}$. The bending section modulus of new steel strip increases 37 times comparing with flat steel strip; its stiffness is increased by 70 times; its tensile strength can be increased 12\% 15\%. The new steel strip is better to deal with the less stable surrounding rock - support lining structure of tunnel and underground engineering. The new steel strip interacts with anchorage system for forming mesh stent and connects dispersed anchors together through new steel strip to forming a whole bearing structure, and then it increases overall bearing effect significantly. Combining with highway tunnel in Gansu province of China for lining concrete structural cracks, this article elaborats in detail the main performance and characteristics of new steel strip and carries on the finite element analysis to the crack section structure on the safety of tunnel lining thickness with ANSYS 11.0 commercial software. Then paper has also been more effective comparative analysis of its secondary lining structure reinforcement measures and puts forward the technical measures for engineering of new steel strip structure reinforcement. This paper provides useful reference and examples for future similer engineering construction quality defects of highway tunnel structure reinforcement rectification work.

The highway tunnel is a kind of underground engineering and has strong concealment, strong unpredictability, bad construction environment, the limitation of construction conditions, risk factors, more complex geology, timeliness and other characteristics. In the construction of highway tunnel, many non-human reason can cause secondary tunnel lining under thick, crack and other defects. If using rework measures, it may cause the demolition difficult, large disturbance to the surrounding rock structure system and the collapse accidents. In the case of less thick lining, not too serious in the lining cracking, basically meet the design requirements and the use of functional, if taking other remedial reinforcement method, it can save costs, shorten construction time remediation. Combining with highway tunnel in Gansu province of China, this article introduced ( new steel strip with carbon fiber and crack perfusion) reinforcing method of secondary lining tunnels in structural less thickness, cracks and other defects and can be reference to futrue similar projects in special rectification.
\end{abstract}

\section{Features of New Steel Materials}

The new steel is a new material of tunnel structure reinforcement and interacts with anchorage system for forming mesh stent and scatters plurality anchors through new steel strip connected 
together to forming a whole bearing structure and increase its overall bearing effect significantly. The bending section modulus of new steel strip increase 37times compared with flat steel strip; its stiffness is increased by 70 times; its tensile strength can be increased $12 \% \sim 15 \%$. The main material of new steel is Q235A and its elastic modulus is $210 \mathrm{GPa}$, Poisson's ratio 0.3, severe $76.93 \mathrm{~N} / \mathrm{m}^{3}$. And mechanical parameters of new steel strip are detailed in table 1 .

Tab. 1 The main technical parameters of new steel

\begin{tabular}{|c|c|c|c|c|}
\hline $\begin{array}{c}\text { Specification } \\
{[\mathrm{mm}]}\end{array}$ & $\begin{array}{c}\text { Cross sectional } \\
\text { area } \\
{\left[\mathrm{mm}^{2}\right]}\end{array}$ & $\begin{array}{c}\text { Yield load } \\
{[\mathrm{KN}]}\end{array}$ & $\begin{array}{c}\text { The yield force } \\
{[\mathrm{KN}]}\end{array}$ & $\begin{array}{c}\text { The Breaking } \\
\text { force } \\
{[\mathrm{KN}]}\end{array}$ \\
\hline $220 \times 2.5$ & 564.4 & 68.3 & 34317 & 246.7 \\
\hline $250 \times 2.75$ & 701.2 & 83.5 & 39277 & 306.6 \\
\hline $280 \times 3.0$ & 853.2 & 100.1 & 43885 & 372.9 \\
\hline
\end{tabular}

\section{The Finite Element Analysis of Crack Lining Structure Safety}

Combining with highway loess tunnel in Gansu province of China,this article carries on analysis of crack section safety and checks tunnel structural safety and guides its overall scheme of reinforcement technology measures.

\section{Computational Model}

The finite element analysis is considered according to the plane strain problem in linear elasticity and the initial stress field of rock only to consider the gravity stress. Figure 1 shows the overall computing load.

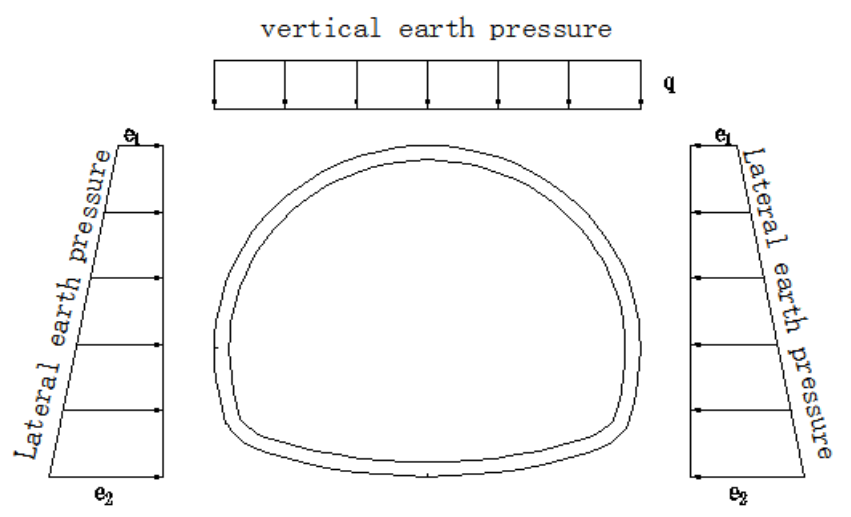

Fig. 1 Schematic diagram of load calculation

\section{Modeling of Finite Element Analysis}

The load calculation and parameter selection reference the relevant provisions in highway tunnel design specification 2004(JTGD70-2004) and the actual situation of the project, surrounding rock of severe $23 \mathrm{KN} / \mathrm{m}^{3}$, surrounding rock elastic force coefficient $\mathrm{K}=200 \mathrm{MPa} / \mathrm{m}$, Poisson's ratio of 0.3 . Elastic modulus of rubble concrete take $26 \mathrm{GPa}$, steel arch elastic modulus $210 \mathrm{GPa}$, severe $78 \mathrm{KN} / \mathrm{m}^{3}$ and its Poisson's ratio 0.3 . According to the highway tunnel construction drawing design documents and test report detailed results, secondary lining cracking segments of tunnel is $\mathrm{V}$ class surrounding rock and lining type is $\mathrm{SVb}$. The main calculation parameters are detailed in Table 2 .

According to the above principles, it establishes the finite element numerical simulation model of tunnel lining structure and related structure internal force that calculated by finite element software ANSYS11.0 is shown in Figure 2, Figure 3. 
Tab. 2 The finite element calculation parameters table of secondary lining structure in tunnel cracking section

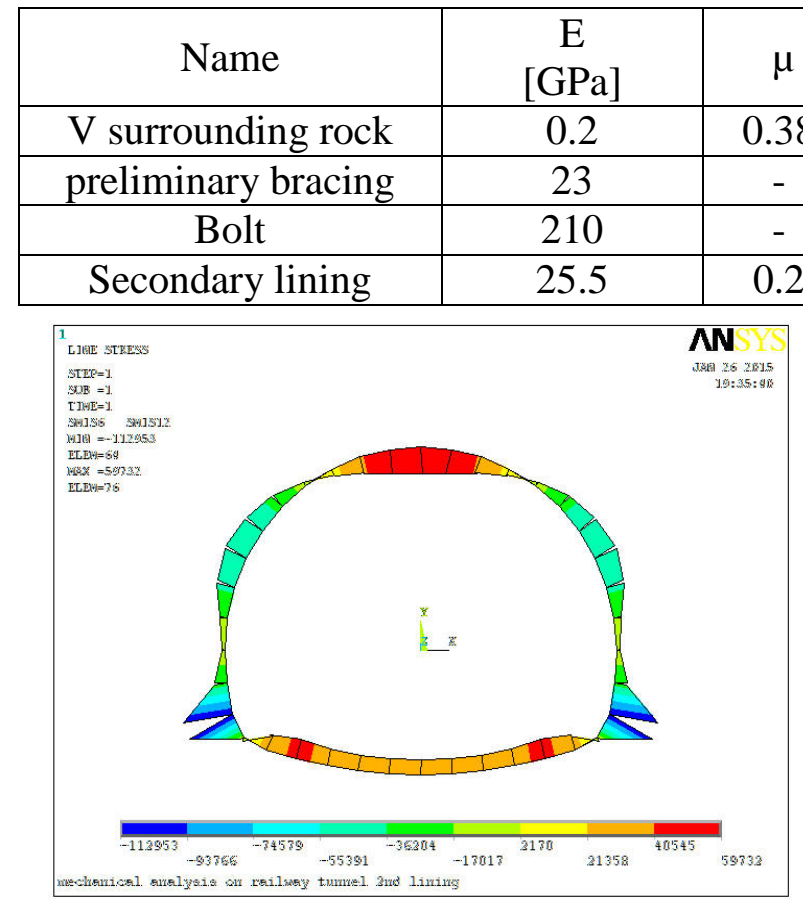

Fig. 2 Moment diagram of tunnel secondary lining structure (unit: N.m)

\begin{tabular}{|c|c|c|}
\hline $\begin{array}{c}\gamma \\
{\left[\mathrm{KN} / \mathrm{m}^{3}\right]}\end{array}$ & $\begin{array}{c}\mathrm{C} \\
{[\mathrm{KPa}]}\end{array}$ & $\begin{array}{c}\varnothing \\
{\left[{ }^{\circ}\right]}\end{array}$ \\
\hline 23 & 45 & 30.5 \\
\hline 22 & - & - \\
\hline 78 & - & - \\
\hline 25 & - & - \\
\hline
\end{tabular}

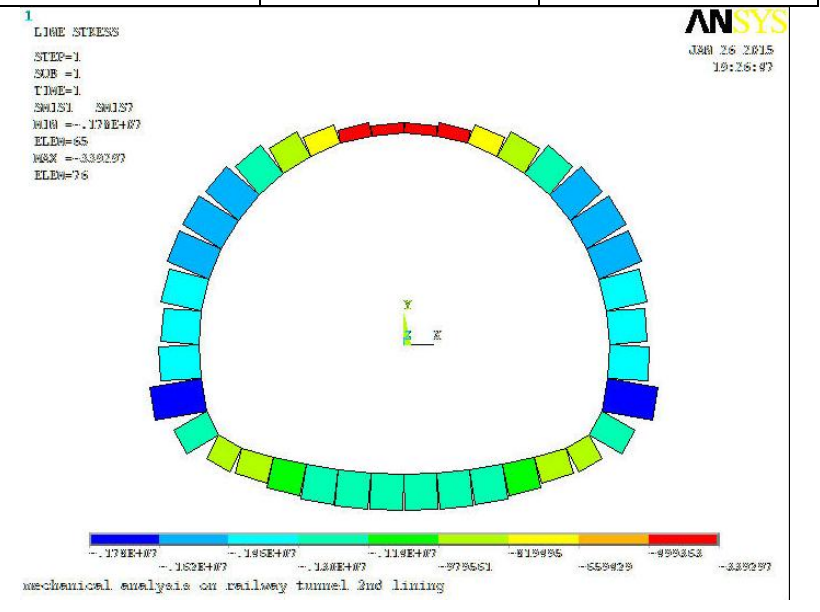

Fig. 3 Axial force diagram of tunnel secondary lining structure (unit: N)

\section{Safety Comprehensive Analysis of Secondary Lining Structure in Crack Section}

It can calculate the displacement of fracture periphery node according to the above calculation model and internal force and then calculate the stress intensity factor of the crack tip by crack tip displacement directly. By stress intensity factor $\mathrm{K}_{\mathrm{I}}$ of type I crack tip and stress intensity factor $\mathrm{K}_{\mathrm{II}}$ of type II crack tip it can get stress intensity factor $\mathrm{K}_{\mathrm{IC}}$ of I-II mixed mode crack tip. Because the tunnel secondary lining cracks is in I-II composite compression shear state, so it neglecte $\mathrm{K}_{\mathrm{I}}$ in negative and just value $\mathrm{K}_{\mathrm{II}}$ and its safety coefficient. Secondary lining of tunnel safety factor is calculated in Eq. 1:

$$
\mathrm{f}=\frac{K_{\mathrm{IC}}{ }^{2}}{4.2 K_{I I}{ }^{2}}
$$

According to the above method the safety factor of secondary lining structure in the tunnel crack section is about 1.31 and it isless than 2.4 in the requirements of the relevant regulations, so the lining cracking segments are at risk. To ensure the safety of lining structure, it should take appropriate measures for remediation projects in dangerous section of secondary lining cracks and make regular inspections on the tunnel in the process of operation to prevent accidents.

\section{The Comparison of Reinforcement Scheme in Lining Structure}

According to the present situation of quality defects in this tunnel construction and combining development trend and potential risks, treatment of construction defects take aim at enhancing the lining thickness insufficient segment and structure safety of lining crack segment in order to maintain bearing capacity of tunnel structure. About three programs may be considered for treatment. Three programs are arch reinforcement scheme, profile steel reinforcement scheme and reinforcement method of new steel strip with carbon fiber and crack perfusion.

The main content of reinforcement method of new steel strip with carbon fiber and 
crack perfusion is as followss: First area of cracks or water leakage are treated and it repair cracks by the carbon fiber cloth and perfusion crack; then the original collapse area use self feeding anchor rod to stabling surrounding rock; after the disease treatment it erect circumferential and longitudinal steel at secondary lining surface. Disadvantages of it are as followss: It destroy surface coating of original structure; the safety margin is acceptable. Advantages of it are as followss: The construction technology is simple; treatment costs is low; it didn't damage original lining. We recommend design unit to using this method because of its advantages.

\section{Technical Measures of Tunnel Lining Structure Reinforcement}

\section{Special Rectification Measures in Secondary Lining of Inadequate Thickness Area}

In secondary lining of inadequate thickness area it use steel reinforcement scheme. It should adopt scheme of new steel strip with carbon fiber and crack perfusion to preprocess the crack when secondary lining occur cracks, then reforce external by steel strip. It should be strengthened and addded waterproofing and drainage measures for crack seepage area and should have be a routine inspection after remediation to prevent accidents. Each applicable types of remediation and support parameters are shown in Table 3 and Table 4.

Tab. 3 Applicable conditions table of types of remediation in design

\begin{tabular}{|c|c|c|}
\hline Number & $\begin{array}{l}\text { Type code of } \\
\text { remediation }\end{array}$ & Applicable conditions \\
\hline 1 & GWLa & $\begin{array}{l}\text { It applies to case of crack and lining thickness less than } \\
\qquad 25 \mathrm{~cm}\end{array}$ \\
\hline 2 & GWLb & $\begin{array}{l}\text { It applies to case of crack and lining thickness enough for } \\
\qquad 25 \mathrm{~cm}\end{array}$ \\
\hline 3 & GTL & $\begin{array}{c}\text { It applies to case of construction collapse and mesh cracks } \\
\text { appearing in the lining }\end{array}$ \\
\hline
\end{tabular}

Tab. 4 Support parameters table of types of remediation in secondary lining design

\begin{tabular}{|c|c|c|c|c|}
\hline $\begin{array}{c}\text { Types of } \\
\text { remediation in } \\
\text { secondary lining }\end{array}$ & $\begin{array}{c}\text { Vertical center } \\
\text { spacing of strip } \\
{[\mathrm{cm}]}\end{array}$ & $\begin{array}{c}\text { Transverse center } \\
\text { spacing of strip } \\
{[\mathrm{cm}]}\end{array}$ & $\begin{array}{c}\text { Strip width } \\
{[\mathrm{cm}]}\end{array}$ & $\begin{array}{c}\text { Strip thickness } \\
{[\mathrm{mm}]}\end{array}$ \\
\hline GTL & 0.4 & 65 & 20 & 5 \\
\hline GWLa & 0.4 & 65 & 20 & 5 \\
\hline GWLb & 0.5 & 65 & 20 & 5 \\
\hline
\end{tabular}

The steel adhesion agent is two-component modified epoxy resin adhesive in remediation process. Strip installation procedure is as follows.

(1)Adhesive surface treatment: Clean the secondary lining surface and strip surface and improve adhesion with colloid to prevent loss before the installation of steel strip. Polish concrete surface with angle grinder till exposing a new surface and clean the dust. Polishe steel with angle grinder till becoming coarse.

(2)Modulation of colloid: First, stir the A, B components, then put A, B groups into the container according to 2: 1 weight ratio. Then stir it with an electric mixer or other bars until the color consistent. Generally modulation of colloid is appropriate to $6-10 \mathrm{~kg}$. The technical performance indicators of steel adhesion agent are shown in Table 5.

(3)The strip first bond with concrete barrel by steel adhesion agent. Circumferential steel strip overlap $20 \mathrm{~cm}$ with circumferential steel strip, and they bond with each other using teel adhesion agent and and are fixed by expansion bolts to prevent falling off. Expansion bolts position should avoid the cracking position. 
(4)It inspect quality of adherend and construction and deal with surface anti-corrosion and other modification.

Tab. 5 The technical performance indicators of colloid of steel adhesion agent

\begin{tabular}{|c|c|c|c|c|c|}
\hline $\begin{array}{c}\text { Colloidal } \\
\text { performance }\end{array}$ & $\begin{array}{c}\text { Tensile } \\
\text { strength }\end{array}$ & $\begin{array}{c}\text { The tensile } \\
\text { modulus of } \\
\text { elasticity }\end{array}$ & $\begin{array}{c}\text { Elonga- } \\
\text { tion }\end{array}$ & $\begin{array}{c}\text { Flexural } \\
\text { strength }\end{array}$ & $\begin{array}{c}\text { Compression } \\
\text { strength }\end{array}$ \\
\hline $\begin{array}{c}\text { Technical } \\
\text { indicators }\end{array}$ & $\geq 30 \mathrm{MPa}$ & $\geq 3500 \mathrm{MPa}$ & $\geq 1.3 \%$ & $\geq 45 \mathrm{MPa}$ & $\geq 65 \mathrm{MPa}$ \\
\hline
\end{tabular}

For expansion bolts in the steel strip installation process, its construction process is as follows.

(1)Drilling: It drill along the border walls $10 \mathrm{~cm}$ inside tunnel by $22 \mathrm{~mm}$ bit and the depth of drilling is $17 \mathrm{~cm}$ and circumferential spacing is $75 \mathrm{~cm}$. The longitudinal spacing refer to table 6 .

Tab. 6 The longitudinal spacing of expansion bolt

\begin{tabular}{|c|c|c|c|}
\hline Type of remediation & GTL & GWLa & GWLb \\
\hline longitudinal spacing of expansion boltd/m & 0.4 & 0.4 & 0.5 \\
\hline
\end{tabular}

(2)Inject glue and install bolts of stainless steel: The length of the bolt into the hole shall not be less than $95 \%$ of the design length. Tighten the nut with wrench to blow open the sleeve quickly, and then remove the nut and the gasket. And then inject steel adhesion agent into the hole.Instal gasket and nut after filling hole, and then tighten and post solid quickly.

(3)When bolt pullout force is larger than $1500 \mathrm{KN}$, it fix nut using a layer of steel adhesion agent to prevent corrosion and shedding during tunnel operations and to ensure safety of pedestrians and vehicles. It should have regularly or irregularly inspection during tunnel operations.

(4)The technology performance of expansion bolt are as followss: Model M16 * 200; its tensile strength is more than or equal to $1250 \mathrm{~kg}$; its shear strength is more than or equal to $650 \mathrm{~kg}$.

\section{Analysis of Structure Safety after the Rectification}

Combining with the earlier calculation method of safety analysis, it do safety analysis of lining structure of three remediation types of GWLa, GWLb and GTL by using ANSYS11.0 software. The calculation results show that: security reserves of lining structure system raise significantly after reinforcement, and the safety factor of secondary lining structure is greater than 2.4 after the rectification and can meet the requirements of the relevant specification.

\section{Some Matters Needing Attention in the Construction}

(1)Treatment of construction quality defects are high risk projects and is not allowed to dispose again and failure. So it must invite construction team that have rich construction experience of tunnel structure reinforcement in order to avoid causing the secondary diseases and economic losses and adverse social affect.

(2)It is ensured that tunnels' structure stress is safe and economy is reasonable and tunnel is applicatable. It should also reduce the use performance of the structure as little as possible and try to avoid the lining dismantling change. It should be ensured that tunnel entity quality satisfies requirements of the tunnel structural and functional

(3)Strip installation avoid all kinds of traffic engineering mark, instrumen, equipment, pipeline facilities and the relevant cavities according to the actual situation. Circumferential steel strip should be installed through spandrel cable tray, lighting facilities and vault fire induction line.

\section{Conclusion}

The tunnel project uses new steel strip technology to replace the traditional tunnel lining reinforcement methods. Then it controls the deformation and fracture of lining effectively and improves tensile deformation capacity and bearing force of the lining, and significantly improves 
the safety of the tunnel structure system. The lining reinforcement method of new steel needs less material and its transportation costs is low and its labor intensity is low and shorten construction time. It can reduce the remediation project investment and shorten the construction period. It provides useful reference experience and working examples for future similar highway tunnel engineering structure reinforcement.

\section{References:}

[1] LI Shun-bo. Application of W-shape Steel Strip in the Primary Support of Gently-inclined Rock Layers of Long Tunnels[J]. Journal of ShiJiaZhuang Institute of Railway Technology, 2013,12(4): 21-26.

[2]Zhang Tuo. W-steel Band Reinforcing Construction Technology of Tunnel Lining Defects[J]. Railway Construction Technology, 2014, (7): 75-77.

[3]SHI Li-guang. The Application of W- shape Steel Str ip in the Disease Management of Railway Tunnel[J]. Sci-tech Information Development \& Economy, 2008, 18(3): 210, 211.

[4]WU Zheng-quan,NIU Zhi-gang. New Process and Finite Element Analysis for W-section Steel Strap[J]. Coal Mine Machinery, 2014, 35(9): 138-140.

[5]LI Yong. et al. Development and application of the steel band of model W[J]. Journal of Henan Mechanical and Electrical Engineering College, 2004, 12(2):16-17.

[6]WU Zheng-quan. NIU Zhi-gang,ZHU Gui-xin. Numerical Simulation of Multi-Pass Roll forming of Mine W-Section Steel Strap[J]. Machinery Design and Manufacture, 2014, (8): 85-88. 